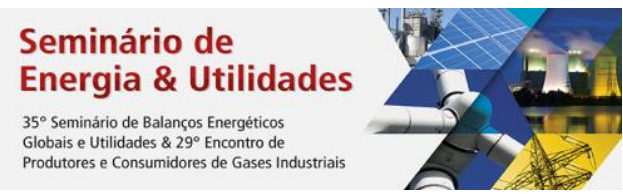

\title{
REDUÇÃO DO CONSUMO DE ÓLEO COMBUSTÍVEL DA CALDEIRA 7 DA CENTRAL TERMOELÉTRICA 1 - CSN*
}

\author{
Luiz Antônio da Silva ${ }^{1}$ \\ José Francisco de Souza² \\ Marcelo Duque da Silva ${ }^{3}$
}

\section{Resumo}

A presente contribuição técnica apresenta os resultados alcançados com a implementação da redução do consumo de óleo combustível nos queimadores frontais do gerador de vapor de número 7 da CTE1, agregando redução de custo operacional na geração de vapor e energia de $50 \mathrm{~Hz}$ da Usina Presidente Vargas. O trabalho aborda os estudos efetuados em relação ao modo operacional na geração de vapor na Caldeira 7 através do consumo de óleo combustível, que até junho de 2012 era consumido segundo uma configuração operacional de 30 t/dia ou ainda $312,5 \mathrm{~kg} / \mathrm{h}$ em cada um dos quatro queimadores da caldeira, o que agregava um custo significativo ao consumo de combustível na CTE1, já que entre os combustíveis utilizados na produção de vapor e energia, o óleo combustível se mostra com o maior custo. A implantação da redução do consumo de óleo combustível de $30 \mathrm{t} /$ dia para 2 t/dia a partir de julho de 2012 teve como benefício a redução do custo de consumo de combustível e consequentemente a redução do custo total de produção de vapor e energia da CTE1.

Palavras-chave: Redução; Consumo; Gerador de vapor.

\section{REDUCTION OF CONSUMPTION OF FUEL OIL BOILER 7 CENTRAL THERMOELECTRIC 1 - CSN}

\section{Abstract}

This technical contribution presents the results achieved by the implementation of the reduction in consumption of fuel oil burners in front of the steam generator number 7 of CTE1, adding operational cost reduction in the generation of steam and power $50 \mathrm{~Hz}$ Presidente Vargas Steelplant The paper discusses the studies done in relation to operational mode to generate steam in the boiler 7 through consumption of fuel oil, which until June 2012 was consumed under an operating setting of $30 \mathrm{t} /$ day or $312.5 \mathrm{~kg} / \mathrm{h}$ in each of the four burners of the boiler, which added a significant fuel consumption in CTE1 cost, since among the fuels used in producing power and steam , fuel oil shown by the higher cost. The implementation of the reduction in fuel oil consumption of $30 \mathrm{t} /$ day to $2 \mathrm{t}$ / day from July 2012 had the benefit of reducing the cost of fuel consumption and consequently reducing the total cost of producing steam and power CTE1

Keywords: Reduction; Consumption; Steam generator.

1 Engenheiro Mecânico, Engenheiro Especialista, Gerência de Geração de Energéticos, CSN, Volta Redonda, RJ, Brasil.

2 Técnico de Eletrônica, Técnico de Desenvolvimento, Gerência de Geração de Energéticos, CSN, Volta Redonda, RJ, Brasil.

3 Técnico em Eletrotécnica - Supervisor de Energético, Gerência de Geração de Energéticos, CSN, Volta Redonda, RJ, Brasil.

* Contribuição técnica ao $35^{\circ}$ Seminário de Balanços Energéticos Globais e Utilidades e $29^{\circ}$ Encontro de Produtores e Consumidores de Gases Industriais, 13 a 15 de agosto de 2014, São Paulo, SP, Brasil. 
Seminário de Energia \& Utilidades $35^{\circ}$ Seminário de Balanços Energéticos Produtores e Consumidores de Gases Industrial

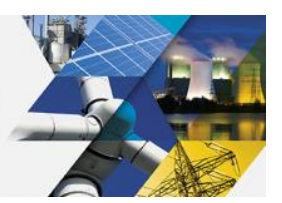

\section{INTRODUÇÃO}

O processo da Central Termoelétrica 1 é composto por 3 caldeiras, cada uma com 4 queimadores de combustíveis, sendo uma delas a Caldeira 7 (Figura 1), que fazem a geração de vapor para a produção de energia elétrica de $50 \mathrm{~Hz}$ na Usina Presidente Vargas (UPV).

O objetivo deste trabalho é apresentar a implementação do modo operacional de consumo reduzido de óleo combustível na Caldeira 7 e redução do custo operacional no consumo de combustível e na produção de vapor e energia de $50 \mathrm{~Hz}$. A Caldeira 7 entrou em operação em 1960 com modo operacional de queima de combustíveis com os gases siderúrgicos (gás de alto forno e gás de coqueria) e óleo combustível. O principal benefício deste trabalho foi de otimizar o processo de produção de vapor e energia de $50 \mathrm{~Hz}$ com redução do custo no consumo de óleo combustível.

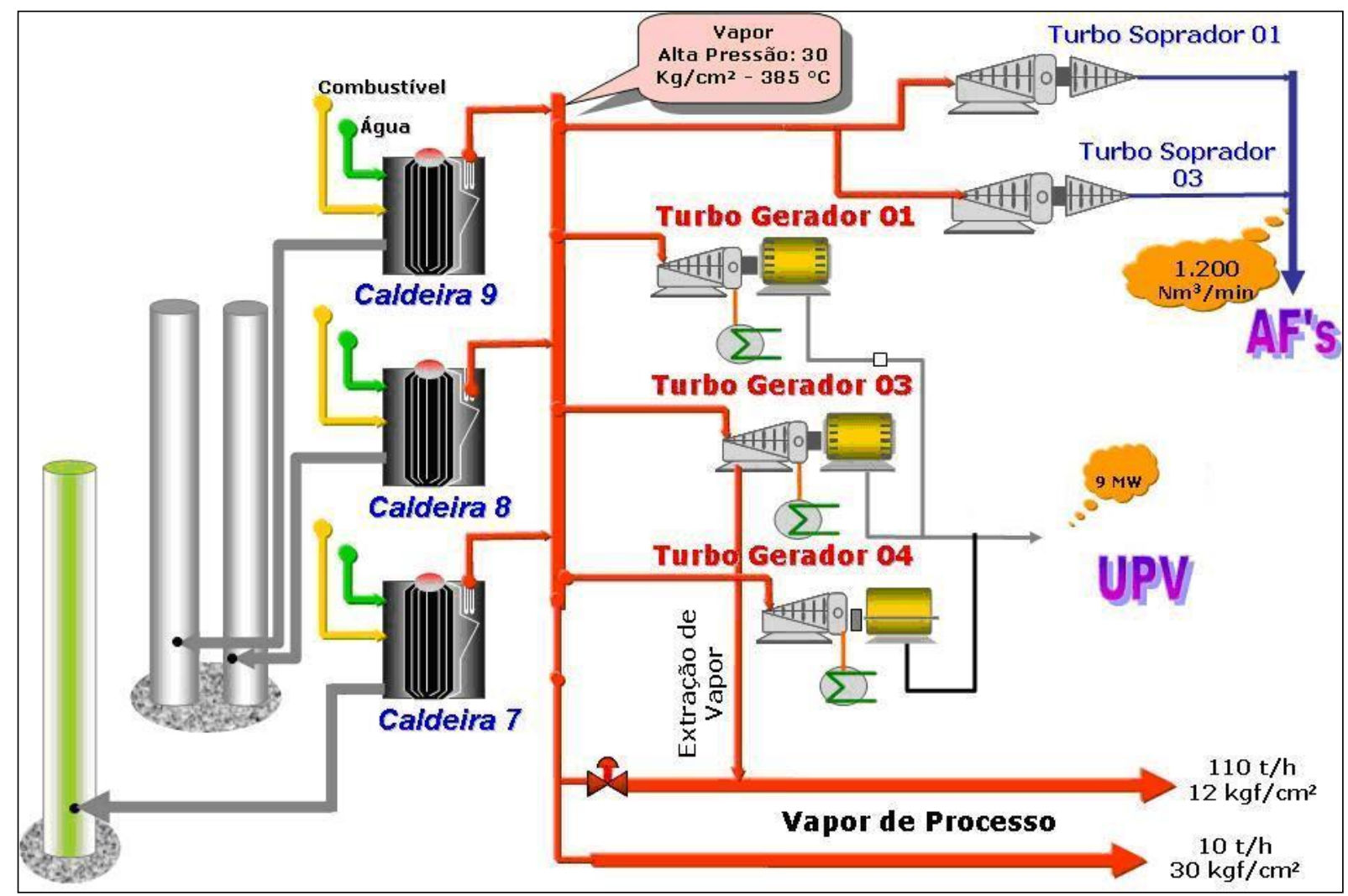

Figura 1. Fluxograma da Unidade Geradora de Energia de $50 \mathrm{~Hz}$.

\section{DESCRIÇÃO DO EQUIPAMENTO}

A Caldeira 7 é um gerador de vapor aquatubular do fabricante Combustion Engineering, fabricada em 1959 com as características destacadas na Tabela 1. Os queimadores são do tipo frontais, em dois níveis com dois queimadores por nível (Figura 2) com suas características destacadas na Tabela 2.

\footnotetext{
* Contribuição técnica ao $35^{\circ}$ Seminário de Balanços Energéticos Globais e Utilidades e $29^{\circ}$ Encontro de Produtores e Consumidores de Gases Industriais, 13 a 15 de agosto de 2014, São Paulo, SP, Brasil.
} 


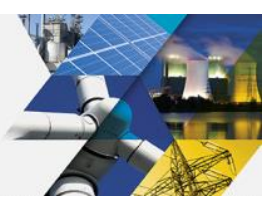

Tabela 1. Dados Técnicos da Caldeira 7 - CTE 1 - CSN

\begin{tabular}{|l|l|}
\hline \multicolumn{2}{|c|}{ DADOS GERAIS - CALDEIRA 7 - CET 1 - CSN } \\
\hline Ano de Fabricação & 1959 \\
\hline Fabricante & COMBUSTION ENGINEERING \\
\hline Capacidade & $90.718 \mathrm{~kg} / \mathrm{h}$ \\
\hline Superfície de Aquecimento & $1876 \mathrm{~m}^{2}$ \\
\hline PMTA & $33,3 \mathrm{kgf} / \mathrm{cm} 2$ \\
\hline Pressão de Teste Hidrostático & $49,88 \mathrm{~kg} / \mathrm{cm} 2$ \\
\hline Pressão de Operação & $30 \mathrm{kgf} / \mathrm{cm} 2$ \\
\hline Temperatura de Saída do Vapor & $385^{\circ} \mathrm{C}$ \\
\hline Combustíveis & GAF, ÓLEO E GCO \\
\hline
\end{tabular}

Tabela 2. Dados dos Queimadores da Caldeira 7 - CTE 1 - CSN

\begin{tabular}{|l|l|}
\hline \multicolumn{2}{|c|}{ DADOS DOS QUEIMADORES - CALDEIRA 7 - CET 1 - CSN } \\
\hline Fabricante & The Babcock e Wilcox Company \\
\hline Vazão de combustível & $80.000 \mathrm{~m}^{3} / \mathrm{h}$ \\
\hline Pressão de Operação & $500 \mathrm{mmCA}$ \\
\hline Temperatura de Operação & $180^{\circ} \mathrm{C}$ \\
\hline Acoplamento & Conjugado - GAF/GCO e Óleo \\
\hline
\end{tabular}



Figura 2. Ilustração do queimador de GCO.

\footnotetext{
* Contribuição técnica ao $35^{\circ}$ Seminário de Balanços Energéticos Globais e Utilidades e $29^{\circ}$ Encontro de Produtores e Consumidores de Gases Industriais, 13 a 15 de agosto de 2014, São Paulo, SP, Brasil.
} 


\section{HISTÓRICO}

Para geração de vapor e energia de $50 \mathrm{~Hz}$ na Central Termoelétrica 1 da Usina Presidente Vargas - CSN a configuração operacional básica atual de combustível na Caldeira 7 é a utilização de gases siderúrgicos produzidos na própria usina, sendo eles Gás de Alto Forno (GAF) e Gás de Coqueria (GCO) e também Óleo Combustível. O GCO é utilizado basicamente como estabilizador de chama em baixa vazão e o GAF é diariamente utilizado em alta vazão para efetivamente produzir vapor e o Óleo Combustível em situação de emergência considerada, por exemplo, quando outros processos necessitam de mais quantidade de vapor de processo não gerado somente na configuração waste gas (gás siderúrgico).

Até meados de junho de 2012 o óleo combustível era consumido segundo uma configuração operacional de uma média de $30 \mathrm{t} / \mathrm{dia}$ ou ainda $312,5 \mathrm{~kg} / \mathrm{h}$ em cada um dos quatro queimadores da caldeira, o que agregava um custo significativo ao consumo de combustível na CTE1, já que entre os combustíveis utilizados na produção de vapor e energia, o óleo combustível se mostra com o maior custo. As Figuras 3 e 4 ilustram o consumo e o custo de óleo combustível para a Caldeira 7 de novembro de 2011 até junho de 2012.



Figura 3. Consumo de Óleo Combustível (Ver Nota 1)

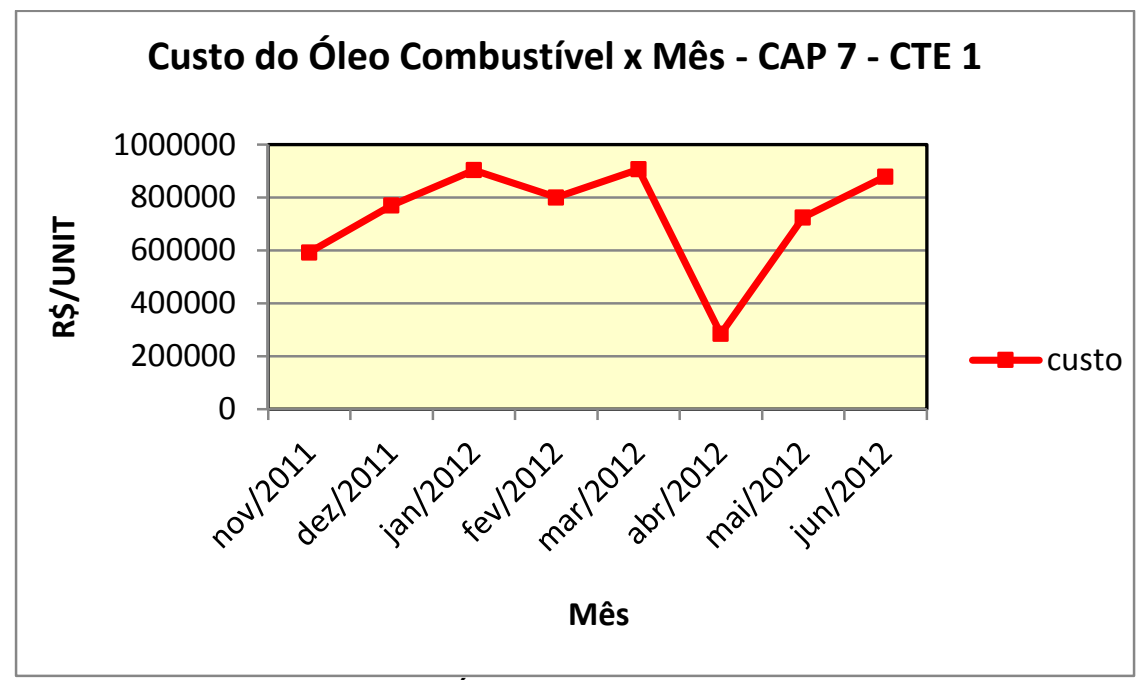

Figura 4. Custo de Óleo Combustível (Ver Nota 1).

* Contribuição técnica ao $35^{\circ}$ Seminário de Balanços Energéticos Globais e Utilidades e $29^{\circ}$ Encontro de Produtores e Consumidores de Gases Industriais, 13 a 15 de agosto de 2014, São Paulo, SP, Brasil. 


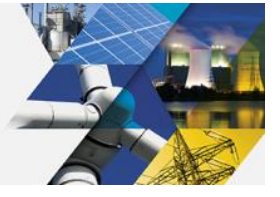

Considerando um preço médio unitário do óleo combustível a $\mathrm{R} \$ 900,00 /$ tonelada, somente nesse período houve um custo médio agregado de $R \$ 732.262,5 /$ mês; utilizando de 30t/dia, motivando a melhor utilização do combustível e consequentemente um melhor modo operacional e uma redução dos custos de processo da CTE1.

\section{DESENVOLVIMENTO DO ESTUDO}

Com o objetivo de otimizar o processo, começou-se as análises pelo projeto, verificando as condições operacionais e um estudo com análise do funcionamento do queimador.

Análise do Projeto: Os queimadores frontais da Caldeira 7, ilustrados na Figura 5, foram confeccionados de acordo com o código de fabricação ASME I e o projeto inicialmente não levou em consideração as instruções atuais da moderna norma NBR 12313.



Figura 5. Ilustração do queimadores da Caldeira 7.

Os queimadores são abastecidos pela mistura de ar e combustível e operam com baixo excesso de ar e baixa emissão de poluentes, tais como particulados e CO. Capacitados para queimar óleos residuais pesados A1 e 9A e gases sejam eles residuais ou não (Figura 6), a Caldeira 7 pode operar somente com gases em condições normais de processo, o que não justifica a utilização de grandes vazões de óleo combustível, que devido ao preço unitário agrega custo significativo ao processo.

Além disso, testes práticos realizados com relação ao modo operacional da CTE 1 com óleo combustível, revelaram que uma quantidade menor de óleo combustível, durante um tempo menor de aplicação, ainda atendem as necessidades de verificação do funcionamento do sistema quanto a vazão, pressão combustão, temperatura do óleo combustível e vazamentos de uma forma geral e posteriormente a necessidade do sistema em situações de emergência. 



Figura 6. Tela de Operação - Queimadores da Caldeira 7.

\section{MODIFICAÇÕES IMPLEMENTADAS}

1) Redução do consumo de óleo combustível de 30t/d para 2t/d (Figuras 7 e 8).

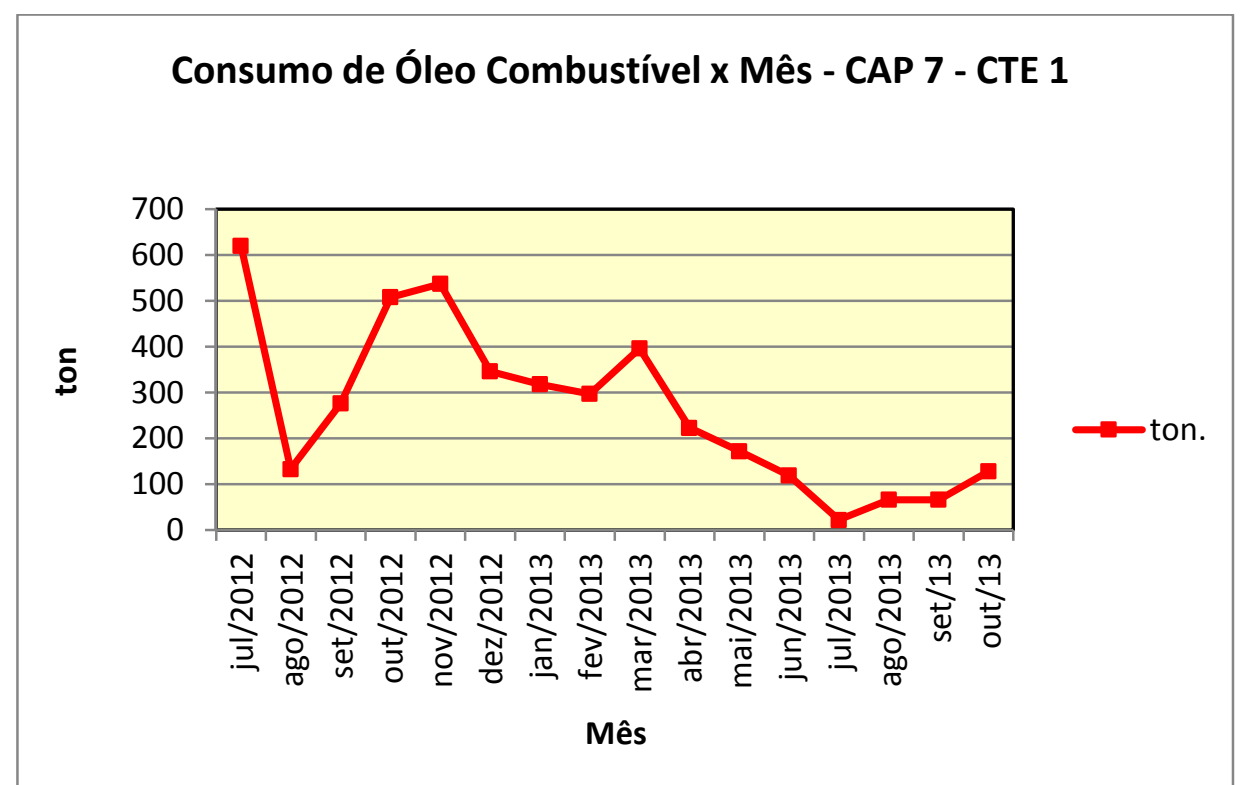

Figura 7. Consumo de Óleo Combustível CAP7 - julho/2012 a outubro/2013

* Contribuição técnica ao $35^{\circ}$ Seminário de Balanços Energéticos Globais e Utilidades e $29^{\circ}$ Encontro de Produtores e Consumidores de Gases Industriais, 13 a 15 de agosto de 2014, São Paulo, SP, Brasil. 


\section{\begin{tabular}{|ll|l|l|}
\hline IDENTIFICAÇÃO DO PROCEDEMENTO - CSN & PP-83246 & REV. 5 & PÁGINA 7/ 14 \\
\hline
\end{tabular}}

8- Utilização de óleo combustível

8.1.1- Consumir 2.0 Ton/h óleo combustível e Reduzir o consumo de GAF dos 4 queimadores da CAP\# 7 para $25 \mathrm{dam}^{3} / \mathrm{h}$, nas seguintes situações, Parada ou partida dos Altos Fornos 2 ou 3;

8.1.2- Desfazer manobras dos selos das redes de GAF, 72", 88".

8.1.3- Após a colocação de óleo, comunicar a Supervisão sobre a ocorrência.

8.1.4- Consumir 1.0 ton./h de óleo combustível em caso de injeção de água no topo

dos altos fornos 2 e 3 (operação realizada quando ocorrer abaixamento de carga).

OBS . : Completando a operação segura, aguardar a conclusão da manobra nos selos, partida ou parada dos Altos Fornos, entrar em contato com operador da CTE-2 SICOM, consultando os valores PCI, verificando se estão adequados para retornar ao consumo normal ("GAF" acima de $700 \mathrm{Kcal} / \mathrm{Hm}^{3}, " \mathrm{GCO}$ " acima de 4000 $\mathrm{Kcal} / \mathrm{Hm}^{3}$ ).

Manter a configuração de combustivel (colocar óleo adicional para estabilização) por 30 minutos após o término da manobra, para assegurar que o gás pobre, (contaminado com nitrogênio ou vapor d'água) seja consumido pela caldeira\#7, uma pequena vazão que não possa causar retrocesso.

8.1.5- Consumir vazão de óleo necessária que atenda a Emergência em caso de TRIP GERAL da CTE\#2, mantendo pressão do vapor em $30 \mathrm{kgf} / \mathrm{cm}^{2}$.

Figura 8. Procedimento Operacional Caldeira 7

2) Rotina de Testes de Consumo de Óleo Combustível (Figura 9);



Figura 9. Registro de Rotina de Testes de Consumo de Óleo Combustível CTE 1 - CAP 7

3) Aumento do tempo de atendimento de emergência de 3 minutos para 7 minutos devido a quantidade menor de óleo combustível (2t/dia) utilizada para suprir a redução de gases siderúrgicos. 


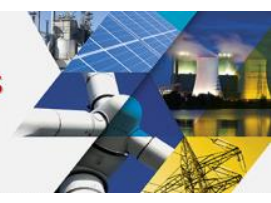

\section{RESULTADOS}

Considerando um intervalo de dezesseis meses, novembro de 2011 a junho de 2012 e julho de 2012 a fevereiro de 2013, isto é, antes e depois da implantação da modificação do modo operacional quanto ao consumo do óleo combustível na Caldeira 7 na CTE 1, podemos observar com números, a redução do custo com o combustível através da Tabela 3 e ainda sim, com a Figura 10.

Tabela 3. Redução do Custo no consumo de Óleo Combustível

\begin{tabular}{|l|c|cc|}
\hline & ANTES (8 meses) & \multicolumn{1}{|c|}{ DEPOIS (8 meses) } \\
\hline CONSUMO DE ÓLEO MÉDIO & $30 \mathrm{t} / \mathrm{dia}$ & $2 \mathrm{t} / \mathrm{dia}$ \\
\hline CUSTO MÉDIO (SEM VARIAÇ̃̃ES DO SISTEMA) & $\mathrm{R} \$ 6.480 .000,00$ & $\mathrm{R} \$$ & $432.000,00$ \\
\hline CUSTO TOTAL (COM VARIAÇõES DO SISTEMA) & $\mathrm{R} \$ 5.858 .100,00$ & $\mathrm{R} \$$ & $2.731 .500,00$ \\
\hline REDUÇÃO DO CUSTO & $\mathrm{R} \$$ & & $\mathbf{3 . 1 2 6 . 6 0 0 , 0 0}$ \\
\hline
\end{tabular}

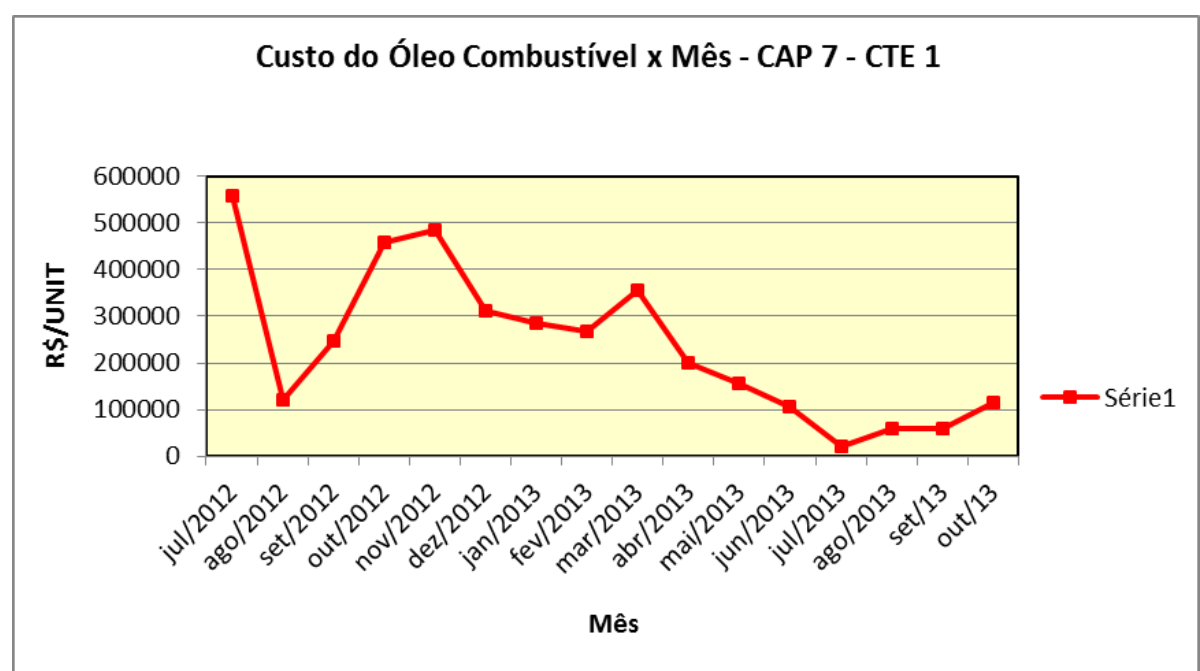

Figura 10. Custo do Óleo Combustível CAP7 - julho/2012 a outubro/2013

\section{CONCLUSÃO}

O trabalho mostrou que e a metodologia desenvolvida pelo grupo foi eficaz e as ações adotadas foram efetivas, pois conseguiu-se otimizar o processo em seu modo operacional, sem comprometer significativamente contingências de emergência e reduzindo o custo no consumo de combustível e consequentemente na geração de energia e vapor na Central Termoelétrica 1 da CSN.

\section{REFERÊNCIAS}

1 Torreira RP. Geradores de Vapor. Companhia melhoramentos;1995.

2 Manual de Instalação e Operação BABCOCK. Caldeiras aquatubular da Central Termoeletrica 1. Volta Redonda; 1969.

3 Woodruff EB, Lammers HB, Lammers TF. Steam Plant Operation. 7th ed. Mc Graw Hill; 1998.

4 Telles PCS. Tubulações Industriais. Rio de Janeiro: Livros Técnicos e Científicos; 1987.

5 Ministério do Trabalho. Manual Técnico - NR-13: Caldeiras e Vasos de Pressão. São Paulo: 2001.

6 American Society of Machanical Engineers. ASME Sections I: Rules for Construciton of Power Boiler; 1995.

7 Brambila PA. Curso de Inspeção de Caldeiras - Instituto Santista de qualidade Industrial [apostila]; 1998.

* Contribuição técnica ao $35^{\circ}$ Seminário de Balanços Energéticos Globais e Utilidades e $29^{\circ}$ Encontro de Produtores e Consumidores de Gases Industriais, 13 a 15 de agosto de 2014, São Paulo, SP, Brasil. 